\title{
Systemic Juvenile Idiopathic Arthritis in two children; case report on clinical course, challenges in diagnosis and the role of FDG-PET/CT-scan
}

Sara Sahba ${ }^{1}$, Arnold Huurnink ${ }^{1}$, Merlijn van den Berg ${ }^{2}$, Berdy Tuitert ${ }^{1}$, Sebastiaan J Vastert $^{3}$, and Gavin ten Tusscher ${ }^{1}$

${ }^{1}$ Dijklander Hospital

${ }^{2}$ Amsterdam UMC Location AMC

${ }^{3}$ Wilhelmina Childrens Hosp

March 1, 2022

\begin{abstract}
Systemic juvenile idiopathic arthritis (sJIA, also called Still's disease) is a rare childhood auto-inflammatory disease with significant morbidity. This case report illustrates the clinical course and highlights diagnostic challenges. FDG-PET/CT imaging may be beneficial in the diagnostic process for some cases, in order to achieve rapid diagnosis and early treatment.
\end{abstract}

\section{Hosted file}

Case Reports Still's Disease.pdf available at https://authorea.com/users/462887/articles/ 558181-systemic-juvenile-idiopathic-arthritis-in-two-children-case-report-on-clinicalcourse-challenges-in-diagnosis-and-the-role-of-fdg-pet-ct-scan 
Figure 1 - FDG-PET/CT scan views of cases

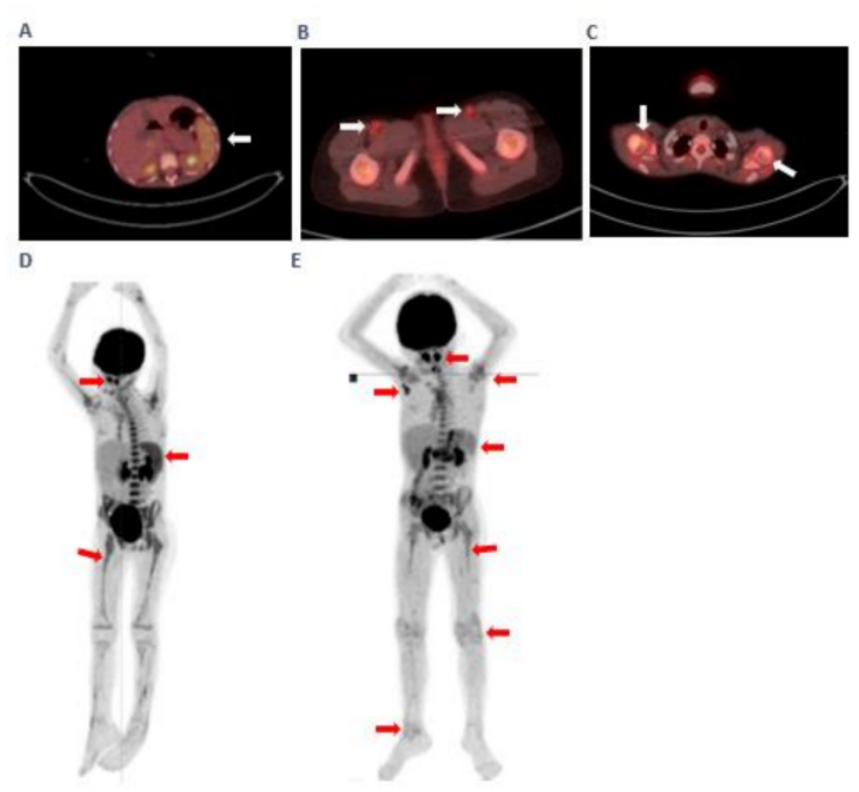

